\title{
Equally Efficient Competitor and the Case of Deutsche Telekom: Economic Perspective
}

\author{
Yasuo Kawashima ${ }^{1}$, Nobufumi Nishimura ${ }^{2}$ \\ ${ }^{1}$ Faculty of Economics, Chuo University, Tokyo, Japan \\ ${ }^{2}$ Faculty of Law, Chuo University, Tokyo, Japan \\ Email address: \\ yasuokaw@tamacc.chuo-u.ac.jp (Y. Kawashima)
}

\section{To cite this article:}

Yasuo Kawashima, Nobufumi Nishimura. Equally Efficient Competitor and the Case of Deutsche Telekom: Economic Perspective. International Journal of Economic Behavior and Organization. Special Issue: Recent Developments of Economic Theory and Its Applications. Vol. 3, No. 2-1, 2015, pp. 39-45. doi: 10.11648/j.ijebo.s.2015030201.17

\begin{abstract}
We examine the implication of the assumption in two types of regulatory environments that a new entrant is an equally efficient competitor, on which the price squeeze test is built. Under partial regulation the entrant exits a market because of the higher access rates set by the authority. If we consider this assumption under no regulation, the entrant exits the market by its own inefficiency, and not by the exclusionary strategies of the incumbent. Regardless of the regulatory environments, the incumbent is not responsible for the exit and the assumption is contradictory to the EC decision.
\end{abstract}

Keywords: Equally Efficient Competitor, Regulatory Environment, Exit of Entrant, 2003 EC Decision, Case of Deutsche Telekom

\section{Introduction}

Deregulation of a network industry, for example, Telecommunications and Water industries, has caused new firms to enter into the market. Some firms may succeed in supplying outputs profitably, while others may exit the market. A price squeeze might have occurred: A vertically integrated firm supplies an input to its downstream competitors at a price that generates a profit margin so low that the competitors exit the market. Thus, price squeeze cases have arisen. When new entrants are forced out of a market, deregulation does not enhance market efficiency. There are several ways to explore whether the entrant is driven out of a market by market competition or by the exclusionary strategies by the incumbent. ${ }^{1}$ Typical examples are given in the U.S. and Europe. In the U.S., a new act is introduced to deal with these issues. In fact, the 1996 Telecommunications Act requires the regulatory authority to examine only whether the access rates for essential inputs are cost based. This is supported by Bork (1978) and Carlton (2008), who insist that the incumbent firm has no incentives to employ a price squeeze. Moreover, Sidak (2008) is

\footnotetext{
1 Weisman (2003) points out two types of exclusionary behavior that the incumbent can adopt: price squeeze and sabotage.
}

skeptical about such an antitrust rule as a price squeeze: When a new entrant exits a market, fining the incumbent can be equivalent to punishing it for failing to ensure its competitor's profitability. In fact, there are situations in which less efficient entrants cannot cope effectively with their competitors.

To judge whether the incumbent firm employs such a strategy, the European Commission (henceforth, EC) proposed two definitions of the Price Squeeze test, ${ }^{2}$ one of which is called the Equally Efficient Competitor (henceforth, EEC) test by Bruno et al. (2013) because it is assumed that a new entrant is an equally efficient competitor to the incumbent firm. This assumption may be called the EEC assumption. The 2003 EC decision on the case of Deutsche Telekom is based crucially on the EEC test. Then, our focus is on this test. Bouckaert and Verboven (2004) introduce regulatory environments to examine properties of the EEC test. It is useful to analyze the implication of the EEC assumption by their definition of regulatory environments.

When we consider the German telecommunication industry, we have to pay attention to paragraph 5 in the European Commission decision of 21 May 2003, which states:

\footnotetext{
${ }^{2}$ See the 1998 Notice of the European Commission (1998).
} 
" Charges for access to local networks are partially regulated by the regulatory authority, but this decision is concerned with unfair prices which have been set by DT itself in the exercise of its own commercial freedom, and for which it is directly responsible."

If the German market can be modeled as a one-shot game where an upstream market is regulated by the authority, the entrant is driven out of the market by high access rates. This means that the the incumbent is not responsible for the exit. To consider whether the incumbent practices a price squeeze, the EC insisted that up- and down-stream markets are not regulated and the exit can be the responsibility of the incumbent. Therefore, the implication of the EEC assumption can be examined in these regulatory environments; under partial regulation and no regulation.

The partial regulation game is modeled as a one shot Cournot game, while the other is modeled as a two stage game. Our model is the same as the one of the important types of market structures in vertically related markets explored by Rey and Tirole (2007). The basic framework and the notation are similar to those of Armstrong (2002) and Bouckaert and Verboven (2004). To proceed with our analysis, we introduce a new criterion to examine the EEC assumption. If the EEC assumption holds, then the test can show precisely whether access rates causes the entrant to exit the market. However, it is easy to show that by the definition of a partial regulation the incumbent is not responsible for the exit. Moreover, access rate set by the authority generates a false negative. If the EEC assumption does not hold, then the EEC test generates a false negative or a false positive depending upon the relative costs of the two competitors. 3

When we turn our attention to the no regulation game, it will be shown that the equally efficient entrant cannot stay in the market at the Subgame Perfect Equilibrium (henceforth, SPE). This means that the exit of the entrant is not due a price squeeze by the incumbent but to insufficient efficiency of the entrant. It will be shown that the entrant can be viable if it can enjoy cost advantage. Under the EEC assumption, the incumbent cannot practice a price squeeze because there is no competitor in the market. This is a game which is discussed by Sidak (2008), who stresses that a price squeeze is a rule that punishes a firm for failing to ensure its competitor's profitability: the equally efficient entrant exits the market because it cannot cope effectively with the incumbent. Thus, the 2003 EC decision of punishing DT for abusive price squeezes, which depends heavily on the EEC test, is not consistent with the EEC assumption. Such concerns about the reliability of the EEC test have been noticed by Weisman (2003) and Bouckaert and Verboven (2004). Salop (2010) proposes a new test to judge whether the incumbent practices such an exclusionary strategy.

Our paper is organized as follows: Section 2 introduces a partial regulation game and the EEC test. We explore the implication of EEC assumption in this game, where the

\footnotetext{
${ }^{3}$ Petulowa and Saavedra (2013) pointed out this fact.
}

authority is responsible for access rates. Section 3 examines the implication of the EEC assumption in the no regulation game, which is modeled as a game with complete and perfect information. We will show that market competition forces the entrant to exit the market. Regardless of the regulatory environments, the EC decision on the case of DT is not well founded. Section 4 summarizes our observations.

\section{EEC Test and Partial Regulation Game}

Consider a network industry with an incumbent firm (firm 1) and a new entrant (firm 2). The incumbent produces an essential input and sells it to the entrant. Thus, foreclosure is assumed away. ${ }^{4}$ Both firms produce outputs in one-to-one proportion. The average cost of an essential input is given by $c_{0}$, which is assumed to be zero for simplicity of our analysis. ${ }^{5}$ The average costs of outputs of firms 1 and 2 are fixed constants $c_{1}, c_{2}+\alpha$, respectively, where $c_{i}$ stands for average costs of firm $i$ without an access rate, and $\alpha$ for the access rate for inputs.

A demand function is given by

$$
P=A-X,
$$

where $P$ is the price of output, $A$ a constant parameter, $\mathrm{X}=x_{1}+x_{2}$, and $x_{i}$ the output of firm $i$. To make our analysis tractable, assume that firms are viable in a partial regulation game in which access rates are determined by the regulatory authority. This assumption is given by

$$
A>2 \times \max \left\{c_{1}, c_{2}\right\} .
$$

These assumptions guarantee that outputs supplied by the firms are positive.

In what follows, the features of the EEC tests will be examined concerning whether a new entrant can get positive profits. ${ }^{6}$ The EEC test which we will consider amounts to examine whether the following inequality is satisfied:

$$
P-\alpha \geq c_{1} \text {. }
$$

Note that it is equivalent to the setting price under the Efficient Component Pricing Rule, when the demand function is linear and the downstream price $P$ is set as $\left(\bar{\alpha}+c_{1}\right)$.

To examine the features of the test, we introduce the new criterion using costs of the entrant. Our criterion directly considers whether the entrant can make positive profits. This is called the profitability (henceforth, PR) criterion, which is

\footnotetext{
${ }^{4}$ Yang and Kawashima (2011) show that the incumbent firm does not have incentives to employ a price squeeze in no regulation games, where upstream and downstream markets are not regulated.

${ }^{5}$ We follow Armstrong (2002) in the sense that upstream costs for producing inputs and the additional upstream costs to the entrants are assumed to be equal to 0 .

${ }^{6}$ For an excellent explanation of price squeeze tests, see Bouckaert and Verboven (2004).
} 
given by

$$
P-\alpha-c_{2}>0
$$

where $\alpha+c_{2}$ is the average cost of outputs by the entrant. This criterion examines if per-unit profits of the entrant are positive. If they are positive, then the entrant can supply outputs profitably and can be viable. Otherwise, the entrant has to exit the market.

The German market in telephone services has been liberalized since 1996, and the Deutsche Telecom has been subject to regulation at both the wholesale and the retail levels. Although the DT has been subject to a price cap for baskets of services, it was given discretion to the pricing strategy of individual component services within the basket. Thus, we consider the German telecommunications market from the viewpoint of the partial regulation game. Although pricing strategy of DT was approved by the German regulatory authority, the entrant was not able to make positive profits and then exited the market. Then, it follows that the pair of access rates set by the authority and the decreases in downstream price by DT were unable to pass the EEC test and then DT was judged that it practiced a price squeeze.

Now, consider a partial regulation game where price for inputs (or access rate) is regulated by the authority. It is a fixed constant and denoted by $\bar{\alpha}$. We will model the partial regulation game as a one shot Cournot game.

The timing of our game is as follows:

1. The authority chooses an access rate $\bar{\alpha}$ for inputs from interval $S_{s q}=\left[0,2 A-c_{1}-c_{2}\right)$.

2. The incumbent and a new entrant compete downstream in supplying outputs.

3. The entrant decides whether it can stay in or leave the market.

4. The authority examines whether the set of access rates and downstream prices can pass the EEC test.

Note that it does not matter whether the productivities of the two firms are different or not if access rates are not so high. $\bar{\alpha}$ is access rate set by the authority. It will be shown in what follows.

In view of (1), profits of the two firms are given respectively by

$$
\begin{gathered}
\pi_{1}=\left(A-x_{1}-x_{2}-c_{1}\right) x_{1}+\bar{\alpha} x_{2}, \\
\pi_{2}=\left(A-x_{1}-x_{2}-\bar{\alpha}-c_{2}\right) x_{2} .
\end{gathered}
$$

Then, we can now establish:

Lemma 1. If the authority sets access rate $\bar{\alpha}<\alpha_{s q}=$ $\frac{A+c_{1}-2 c_{2}}{2}$, then the outputs of the incumbent and the entrant, and the price of the outputs under the partial regulation game are given by

$$
\begin{aligned}
& \bar{x}_{1}=\frac{A-2 c_{1}+c_{2}+\bar{\alpha}}{3}>0, \\
& \bar{x}_{2}=\frac{A+c_{1}-2 c_{2}-2 \bar{\alpha}}{3}>0,
\end{aligned}
$$

$$
\begin{gathered}
X=\bar{x}_{1}+\bar{x}_{2}=\frac{2 A-c_{1}-c_{2}-\bar{\alpha}}{3}>0, \\
\bar{P}=A-\bar{X}=\frac{A+c_{1}+c_{2}+\bar{\alpha}}{3}>0 .
\end{gathered}
$$

However, the entrant cannot enter the market for $\alpha_{s q} \leq \bar{\alpha}<\left(2 A-c_{1}-c_{2}\right)$.

Proof. Differentiating profits $\pi_{i}$ with respect to $x_{i}$ yields the first order conditions of firm $i$ :

$$
\begin{gathered}
\frac{\partial \pi_{1}}{\partial x_{1}}=\left(A-2 x_{1}-x_{2}-c_{1}\right)=0, \\
\frac{\partial \pi_{2}}{\partial x_{2}}=\left(A-x_{1}-2 x_{2}-\bar{\alpha}-c_{2}\right)=0 .
\end{gathered}
$$

Solving $x_{i}$ yields outputs of the two firms,

$$
\bar{x}_{1}=\frac{A-2 c_{1}+c_{2}+\bar{\alpha}}{3}, \quad \bar{x}_{2}=\frac{A+c_{1}-2 c_{2}-2 \bar{\alpha}}{3} .
$$

Substituting these into $X$ and (1), we get

$$
\bar{P}=\frac{A+c_{1}+c_{2}+\bar{\alpha}}{3} \text {. }
$$

If access rate $\bar{\alpha}$ is less than $\left(A+c_{1}-2 c_{2}\right) / 2$, then the output $\bar{x}_{i}$ is positive.

If access rate $\bar{\alpha}$ is not less than $\alpha_{s q}$, then the entrant cannot make positive profits and then it cannot stay in the market. Total outputs can be positive if the access rate is less than $\left(A+c_{1}-2 c_{2}\right) / 2$.

It then follows from Lemma 1 that the downstream price is determined by the access rate and that it increases with the access rates.

When we apply the EEC test (3) to the partial regulation game, it is easy to show that

$$
\bar{P}-\bar{\alpha}-c_{1}=\frac{A-2 c_{1}+c_{2}-2 \bar{\alpha}}{3} \geq 0
$$

if and only if

$$
\bar{\alpha} \leq \tilde{\alpha}=\frac{A-2 c_{1}+c_{2}}{2} .
$$

The result of the PR criterion (4) is given by

$$
\bar{P}-\bar{\alpha}-c_{2}=\frac{A+c_{1}-2 c_{2}-2 \bar{\alpha}}{3}>0
$$

if and only if

$$
\bar{\alpha}<\alpha_{s q}=\frac{A+c_{1}-2 c_{2}}{2} .
$$

Note that $\tilde{\alpha}$ and $\alpha_{s q}$ are both less than $A$ in view of (2).

The entrant cannot make positive profits and exits the market if the authority sets access rates equal to $\alpha_{s q}$.

It would be easy to show the above arguments by the use of the EEC and the PR lines, which are given respectively by

$$
P-\alpha-c_{1}=0,
$$




$$
P-\alpha-c_{2}=0 .
$$

They are depicted in Figures 1 and 2 with the Downstream Price line (or DP), which is given by

$$
P=\frac{A+c_{1}+c_{2}+\alpha}{3} .
$$

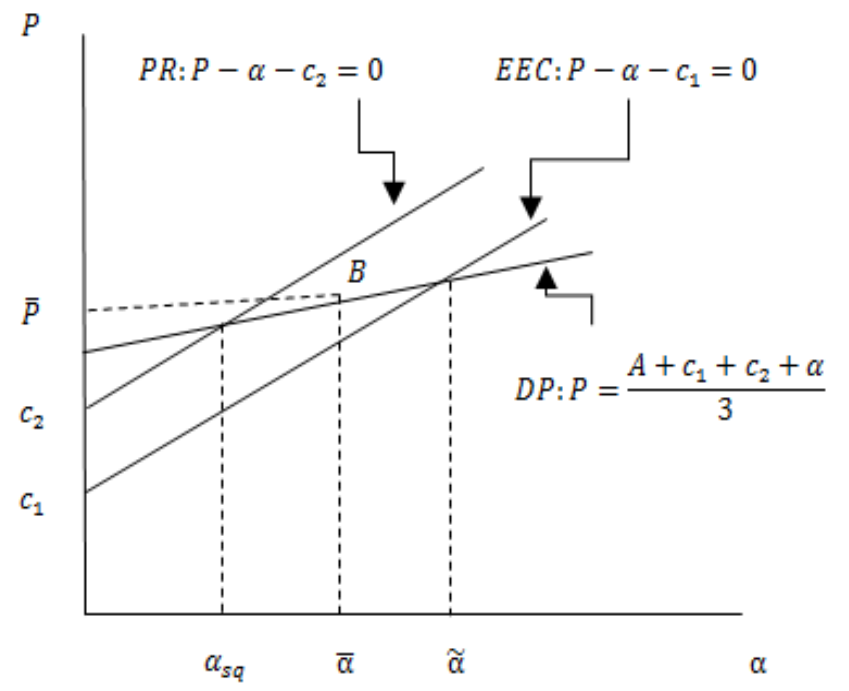

Fig. 1. False Negative $\left(c_{1}<c_{2}\right)$

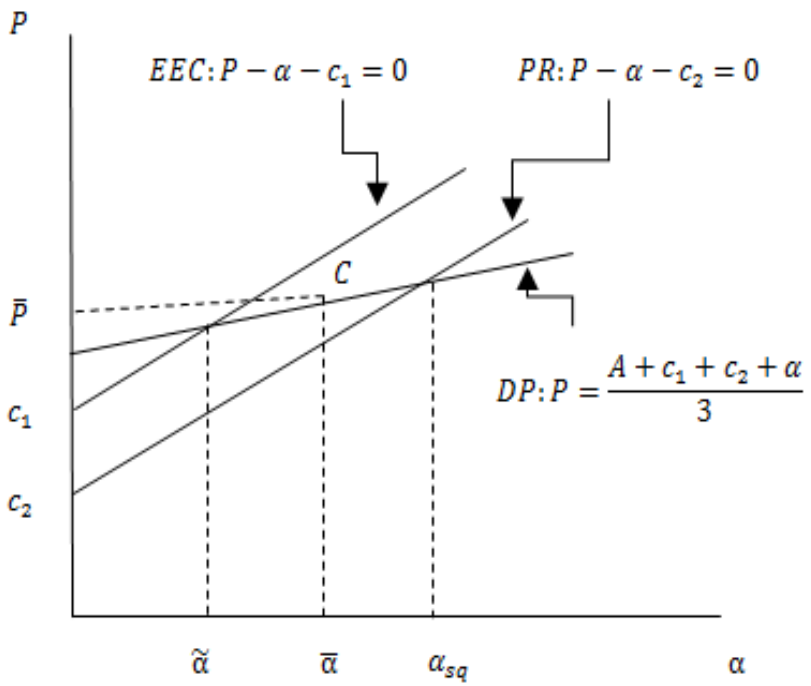

Fig. 2. False Positive $\left(c_{1} \geq c_{2}\right)$

In what follows, consider first a game where the entrant is less efficient: i.e., $c_{1}<c_{2}$. Then, the EEC line is below the PR line. Thus, Figure 1 shows that $\alpha_{s q}<\tilde{\alpha}$. However, if $c_{1} \geq c_{2}$, then the EECline is above the PR line. Thus, Figure 2 shows that the intersection point of the EEC and the DP lines is left to that of the PR and the DP lines. Then, from Figure 2 we conclude that $\alpha_{s q} \geq \tilde{\alpha}$.

Comparing Figures 1 with 2, it is straightforward to show that

$$
\alpha_{s q} \gtreqless \tilde{\alpha} \quad \text { iff } \quad c_{1} \gtreqless c_{2} .
$$

Note that if the output and/or the profit of a firm is not positive, then the firm has to exit the market.
We can now summarize our results as:

Lemma 2. Depending upon the values of the access rates set by the authority, there are two games in which the entrant is forced out of the market:

Case 1: If the entrant is less efficient than the incumbent, then the entrant cannot stay in the market for the access rate $\bar{\alpha}$ larger than $\alpha_{s q}$. If the access rate is in the closed interval $\left[\alpha_{s q}, \tilde{\alpha}\right]$, then it generates a false negative.

Case 2: If the entrant can enjoy efficiency advantage, and the access rate is not less than $\alpha_{s q}$, then the entrant exits the market. Moreover, a false positive is generated for $\bar{\alpha} \in\left(\tilde{\alpha}, \alpha_{s q}\right)$. Especially, the equally efficient entrant exits the market for the access rate not less than $\frac{(A-C)}{2}$.

Proof. Case 1: This game is shown in Figure 1. If access rate $\bar{\alpha}$ is larger than $\alpha_{s q}$, the PR line is above the EEC line. This means that the entrant can not get positive profits. For $\bar{\alpha} \in\left[\alpha_{s q}, \tilde{\alpha}\right]$, the PR criterion is not passed, but the EEC test can be passed. A false negative arises. For example, see point $\mathrm{B}$ in Figure 1.

Case 2: This is a game which is shown in Figure 2. If the access rate is larger that $\alpha_{s q}$, then the PR line is above the EEC line. It follows that the entrant cannot be viable. Especially, if $\bar{\alpha}$ is in $\left(\tilde{\alpha}, \alpha_{s q}\right)$, then $\bar{\alpha}$ and the market price $P$ meet the PR criterion, but the test cannot be passed. Thus, $\bar{\alpha}$ leads to a false positive. An example is shown in point $\mathrm{C}$ in Figure 2.

If the EEC assumption holds: i.e., $c_{1}=c_{2}=c$, the EEC and the PR lines coincide. Then, we have $\alpha_{s q}=\tilde{\alpha}=\frac{(A-c)}{2}$. The access rate higher than $\frac{(A-C)}{2}$ leads the entrant to exit the market.

Note that it does not matter whether the entrant is more efficient than the incumbent in a partial regulation game. This is because an access price is set by the authority and then the entrant is less squeezed with its profits in an upstream market than in no regulation game. Note that less efficient entrants cannot be viable in no regulation game. ${ }^{7}$

In short, we find that there is one basic factor: high access rates set by the authority. In view of Lemma 2, we can now conclude that the incumbent firm is not responsible for the exit of the equally efficient entrant in the partial regulated game, but the authority is.

However, based on Lemma 2 and the access rates set by the authority, we can easily establish:

Proposition 1. If the German telecommunication market is partially regulated, then the decision of the EC on the case of DT is not well founded.

Proof. It follows from Lemma 2 that the entrant is forced out of the market because the access rate set by the authority is high enough. Then, DT is not responsible for the exit, but the authority is.

\footnotetext{
${ }^{7}$ For example, see Bork (1978) and Carlton (2008) in which a downstream market is competitive, and Yang and Kawashima (2011) in which a downstream market is a duopoly. Moreover, this will be shown in what follows.
} 


\section{EEC Test in No Regulation Game}

Next, consider a not regulated game in which the upstream market is not regulated. As pointed out in the Introduction, this is the game in which the EC considers what the German telecommunication market really is. As pointed out above, the incumbent is not responsible for profitability of the entrant if access rate is set by the authority. However, if the incumbent can set upstream price, then there is the possibility that the incumbent is responsible for the exit of the entrant. It is time to consider a no regulation game. This game is modeled as a two-stage game with complete and perfect information. The timing of this game is as follows:

1.The incumbent chooses access rate $\bar{\alpha}$ from interval $S_{s q}=\left[0,2 A-c_{1}-c_{2}\right)$.

2.The two firms compete in supplying outputs in a downstream market.

To proceed with our analysis, assume that

$$
c_{1}>c_{2} \text {. }
$$

Combining (2) and (5), we have

$$
A \geq 2 c_{1} .
$$

This assumption will take the place of (2) in what follows. In fact, this is a more useful and more direct expression than (2). A demand function is given by (1).

In the second stage, their profits are expressed as

$$
\begin{gathered}
\pi_{1}=\left(P-c_{1}\right) x_{1}+\alpha x_{2} \\
\pi_{2}=(P-\alpha) x_{2}
\end{gathered}
$$

The best response functions are given respectively by

$$
\frac{\partial \pi_{i}}{\partial x_{i}}=0 \text { for } i=1,2 .
$$

It follows that if the access rate $\alpha$ set by the incumbent is less than $\alpha_{s q}$, then the outputs of the firms and the price are as shown in Lemma 1. However, it follows from Lemma 1 that the entrant cannot enter into the market if $\alpha$ is not less than $\alpha_{s q}$. In what follows, our focus is mainly on the former game where $\alpha$ is less that $\alpha_{s q}$.

In the first stage, the incumbent maximizes its profit given demand for inputs. Noting that one unit of output is produced with one unit of input, demand for inputs is given by the outputs of the entrant, which is shown in Lemma 1: $\bar{x}_{2}=\frac{A+c_{1}-2 c_{2}-2 \alpha}{3}$ and $\bar{P}=\frac{A+c_{1}+c_{2}+\alpha}{3}$ if $\alpha$ is less than $\alpha_{s q}$.

Substituting outputs $\bar{x}_{i}$ and price $\bar{P}$ into the profit of the incumbent yields

$$
\pi_{1}(\alpha)=\left(\bar{P}-c_{1}\right) \bar{x}_{1}+\alpha x_{2}=\left(\frac{A-2 c_{1}+c_{2}+\alpha}{3}\right)^{2}+\frac{\alpha\left(A+c_{1}-2 c_{2}-2 \alpha\right)}{3} .
$$

The first order condition is

$$
\frac{\partial \pi_{1}(\alpha)}{\partial \alpha}=\frac{\left(5 A-c_{1}-4 c_{2}-10 \alpha\right)}{9}=0 .
$$

The optimal access rate is given by

$$
\alpha^{*}=\frac{5 A-c_{1}-4 c_{2}}{10}>0,
$$

where the inequality is due to (5) and (6).

It is easy to show that

$$
\tilde{\alpha}<\alpha^{*}<\alpha_{s q}
$$

where the inequalities are due to (5).

Noting that the profit function of the incumbent is quadratic, for $\bar{\alpha} \in S_{s q}$,

$$
\pi\left(\alpha^{*}\right) \geq \pi(\bar{\alpha})
$$

where the equality holds at $\bar{\alpha}=\alpha^{*}$.

Thus, maximum profits can be achieved by supplying inputs to its competitor and the incumbent does not have incentives to employ a price squeeze.

The monopolization of the downstream market provides additional profit to the incumbent and at the same time the incumbent loses a customer in the upstream market. This causes loss of profits to the incumbent. Thus, it is not straightforward that additional profits overcome the upstream loss. However, the loss in the upstream market turns out to be larger than the additional profits in the downstream market. Carlton (2008) is correct in pointing out that the monopolization of both markets does not enable the incumbent to get maximum profits.

Next, we can determine SPE (Subgame Perfect Equilibrium) in the no regulation game. Substituting $\alpha^{*}$ into $\bar{x}_{i}$, and $\bar{P}$ in Lemma 1 yields equilibrium outputs and prices.

We can summarize these results as follows:

Lemma 3. In the not regulated game where a new entrant can enjoy costs advantage, equilibrium outputs and prices are expressed respectively as,

$$
\begin{gathered}
x_{1=}^{*} \frac{5 A-7 c_{1}+2 c_{2}}{10}>0, \\
x_{2}^{*}=\frac{2\left(c_{1}-c_{2}\right)}{5}>0, \\
X^{*}=\frac{\left(5 A-3 c_{1}-2 c_{2}\right)}{10}>0, \\
P^{*}=\frac{5 A+3 c_{1}+2 c_{2}}{10}>0 .
\end{gathered}
$$

However, if the entrant cannot be superior in costs to the incumbent, then a market is monopolized by the incumbent.

It is easy to show that SPE in the no regulation game generates a false positive. In fact, substituting $P^{*}$ and $\alpha^{*}$ into (3) and (4) yields

$$
\begin{aligned}
& P^{*}-\alpha^{*}-c_{1}=\frac{3}{5}\left(c_{2}-c_{1}\right)<0, \\
& P^{*}-\alpha^{*}-c_{2}=\frac{2}{5}\left(c_{1}-c_{2}\right)>0,
\end{aligned}
$$

where these inequalities are due to (5).

Note also that outputs of the entrant depend solely on the 
cost difference of the firms. If the entrant can enjoy advantage in costs, it can get positive profits and can stay in the market. However, if it cannot, then the entrant cannot stay in the market. The intuition behind this is simple: the entrant cannot have cost advantage because access rate is larger than the cost of input. Note that efficiency is the same to the firms: One unit of outputs is produced with one unit of inputs and then the entrant cannot cope effectively with the incumbent if it is inferior in costs. Disadvantages in costs play a crucial role in market competition. This argument can be summarize as follows:

Proposition 2. The assumption that a new entrant is an equally efficient competitor is not consistent with the 2003 EC decision that the entrant is driven out of the market by a price squeeze.

Proof. If the entrant is an equally efficient competitor; i.e., $c_{1}=c_{2}$, then Lemma 3 implies that output $x_{2}^{*}$ is equal to zero. The equally efficient entrant cannot make positive profits and is driven out of the market by its inability to cope effectively with the incumbent, not by the exclusionary strategies such as a price squeeze. In other words, there is no competitor in the market so that the incumbent does not practice a price squeeze.

It is interesting to note that the entrant exits the market not by exclusionary strategy such as a price squeeze by the incumbent, but by its own inefficiency. Moreover, the incumbent does not have incentives to employ such an exclusionary strategy. It then follows from these arguments that the entrant can not be viable because it can not be superior in costs to the incumbent. In other words, market competition leads the inefficient entrant to exit the market. Thus, market competition will enhance market efficiency. Games in which the entrant does not enjoy costs advantage and the incumbent was fined for abusive price squeeze are situations which were discussed by Sidak (2008). In fact, Sidak (2008) criticizes the antitrust rule that punishes a firm for failing to ensure its competitor's profitability. The punishment of the incumbent does not guarantee that more efficient firms enter the market and promote market efficiency.

\section{Conclusions}

This paper has analyzed the implication of the assumption in two distinct types of regulatory environments that the entrant is equally efficient competitor. If the entrants are equally efficient under partial regulation, then it is shown that a high access rate leads the entrant to exit the market. Noting that access rates are set by the authority, the exit is not caused by the exclusionary strategies such as a price squeeze by the incumbent. As this is a game in which the incumbent is not responsible for the exit of the entrant, DT cannot exclude the entrant from the market by the definition of the environment. Thus, we next consider the implication under no regulation.

The no regulation game is analyzed by a game with complete and perfect information. Subgame Perfect Equilibrium generates a false own negative in this test, and the equally efficient entrant exits the market because of its own inefficiency. Although the upstream and the downstream markets are not regulated, the incumbent has no incentives to employ a price squeeze. Thus, the entrant is forced out of the market by market competition, and not by exclusionary strategies such as a price squeeze. This means that the incumbent is not responsible for the exit of the entrant.

Regardless of the regulatory environment of the German telecommunication market, the EC decision in the case of DT is not well founded. The assumption that a new entrant is an equally efficient competitor is contradictory to the $2003 \mathrm{EC}$ decision of fining DT for a price squeeze, though the EC judges the case of DT solely by the EEC test.

\section{Acknowledgements}

The suggestions and advices given by Professors Toichiro Asada, Akio Matsumoto, Masahiro Yabuta of Chuo University, and Shumei Hirai of Seinan Gakuin University are highly appreciated by the authors of this paper. This paper is dedicated to Professor Toshikazu Ito on the occasion of his retirement at Ryukoku University.

\section{References}

[1] Armstrong, M. (2002),"The Theory of Access Pricing and Interconnection" in The Handbook of Telecommunications Economics (Vol 1)., ed. by M. Caves et al., Amsterdam, The Netherlands: North-Holland; 297-384.

[2] Bork, R. (1978), The Antitrust Paradox: A Policy at War with Itself, New York: Basic Books.

[3] Bouckaert, J. and Verboven, F. (2004), "Price Squeezes in a Regulatory Environment," Journal of Regulatory Economics, 26(3), .321-51.

[4] Bruno, J, Rey, P. and Saavedra, C. (2013), "The Economics of Margin Squeeze," IDIE Report.

[5] Carlton, W. (2008), "Should "Price Squeeze" Be a Recognized Form of Anticompetitive Conduct?", Journal of Competition Law and Economics, 4(2), 271-278.

[6] European Commission (1998), "Notice on the Application of the Competition Rules to Access Agreements in the Telecommunications Sector," 98/C: 265/02. (also in Official Journal of the European Union C 265, 22/08/1998: 2-28.)

[7] European Commission (2003), "Commission Decision of 21 May 2003 relating a proceeding under Article 82 of the EC Treaty ", Official Journal of the European Union L 263, 9-41.

[8] Petulowa, M. and Saavedra, C. (2013),"Margine Squeeze in a Regulatory Environment: An Application to Differentiated Product Markets", mimeo.

[9] Rey, P. and Tirole, J. (2007), "A Primer on Foreclosure," in Handbook of Industrial Organization Vol.3, ed. by M. Armstrong and R.H. Porter, Amsterdam, The Netherlands: North-Holland, 2145-2220.

[10] Salop, S. (2010), "Refusals to Deal and Price Squeeze By an Unregulated, Vertically Integrated Monopolist," Antitrust Law Journal, 76(3), 709-740. 
[11] Sidak, J. G. (2008), “Abolishing the Price Squeeze as a Theory of Antitrust Liability", Journal of Competition Law and Economics, 4(2), 279-309.

[12] Weisman, D. L. (2003), "Vertical Integration and Telecommunications," in The International Handbook of
Telecommunications Economics Vol.1, ed. by G. Madden, Northampton, MA: Edward Elgar, 232-255.

[13] Yang, C. and Kawashima, Y. (2011), "Is Price Squeeze Optimal Strategy for Integrated Firms ?," Discussion Paper No. 171, Institute of Economic Research, Chuo University. 